\title{
Intracellular Porphyromonas gingivalis Promotes the Tumorigenic Behavior of Pancreatic Carcinoma Cells
}

\author{
JebaMercy Gnanasekaran ${ }^{1}$, Adi Binder Gallimidi 1,2, Elias Saba ${ }^{1}$, Karthikeyan Pandi ${ }^{1}$, \\ Luba Eli Berchoer ${ }^{1}$, Esther Hermano ${ }^{2}$, Sarah Angabo ${ }^{1}$, Hasna'a Makkawi ${ }^{1}$, Arin Khashan ${ }^{1}$, \\ Alaa Daoud ${ }^{1}$, Michael Elkin ${ }^{2, *,+}$ and Gabriel Nussbaum ${ }^{1, *, \dagger}$ \\ 1 The Institute of Dental Sciences, Hebrew University, Hadassah Faculty of Dental Medicine, \\ Jerusalem 9112102, Israel; jebmercy@gmail.com (J.G.); adi.binder@mail.huji.ac.il (A.B.G.); \\ elias.saba@mail.huji.ac.il (E.S.); karthike.pandi@mail.huji.ac.il (K.P.); lubae@ekmd.huji.ac.il (L.E.B.); \\ Sarah.angabo@mail.huji.ac.il (S.A.); hasnaa.makkawi@mail.huji.ac.il (H.M.); \\ arin.khashan@mail.huji.ac.il (A.K.); alaa.daoud@mail.huji.ac.il (A.D.) \\ 2 Sharett Oncology Institute, Hadassah-Hebrew University Medical Center, Jerusalem 9112102, Israel; \\ estherhermano@gmail.com \\ * Correspondence: melkin@hadassah.org.il (M.E.); gabrieln@ekmd.huji.ac.il (G.N.); \\ Tel.: +972-2-6776782 (M.E.); +972-2-6758581 (G.N.) \\ + Equal contribution (these authors share the senior authorship).
}

Received: 2 July 2020; Accepted: 14 August 2020; Published: 18 August 2020

\begin{abstract}
Porphyromonas gingivalis is a member of the dysbiotic oral microbiome associated with oral inflammation and periodontal disease. Intriguingly, epidemiological studies link P. gingivalis to an increased risk of pancreatic cancer. Given that oral bacteria are detected in human pancreatic cancer, and both mouse and human pancreata harbor microbiota, we explored the involvement of $P$. gingivalis in pancreatic tumorigenesis using cell lines and a xenograft model. Live $P$. gingivalis induced proliferation of pancreatic cancer cells; however, surprisingly, this effect was independent of Toll-like receptor 2, the innate immune receptor that is engaged in response to $P$. gingivalis on other cancer and immune cells, and is required for $P$. gingivalis to induce alveolar bone resorption. Instead, we found that $P$. gingivalis survives inside pancreatic cancer cells, a trait that can be enhanced in vitro and is increased by hypoxia, a central characteristic of pancreatic cancer. Increased tumor cell proliferation was related to the degree of intracellular persistence, and infection of tumor cells with $P$. gingivalis led to enhanced growth in vivo. To the best of our knowledge, this study is the first to demonstrate the direct effect of exposure to $P$. gingivalis on the tumorigenic behavior of pancreatic cancer cell lines. Our findings shed light on potential mechanisms underlying the pancreatic cancer-periodontitis link.
\end{abstract}

Keywords: Porphyromonas gingivalis; periodontitis; pancreatic neoplasms; tumor hypoxia; carcinogenesis

\section{Introduction}

Pancreatic ductal adenocarcinoma (PDAC) is among the most aggressive and least treatable forms of cancer [1]. PDAC develops in an inflammatory environment that is present even in low-grade premalignant lesions from individuals without a history of acute or chronic pancreatitis [2]. Several studies demonstrate an association between PDAC and periodontitis, a common and chronic inflammatory disease of the oral cavity that is driven by a dysbiotic microbiome [3-5]. Periodontal disease may influence pancreatic cancer by elevating inflammatory mediators that promote tumor development, or by direct effects of bacteria on tumor cells or their microenvironment. A large, prospective, population based-study demonstrated a highly significant association between carriage of Porphyromonas gingivalis (P. gingivalis), and the risk of pancreatic cancer development [4]. P. gingivalis is 
a gram negative, anaerobic bacteria that thrives in the inflamed environment of periodontal lesions, and escapes the bactericidal activity of innate immune cells by activating Toll-like receptor 2 (TLR2) signaling through PI3K [6,7]. P. gingivalis is linked to several extra-oral disorders, and migrates to tissues remote from the oral cavity [8-13]. Oral bacteria are found in PDAC samples, and both mouse and human pancreata harbor microbiota [14-17], although how oral pathogens reach and invade pancreatic tissue has not been addressed. Hematogenous spread is a likely route of access for oral pathogens since transient bacteremia follows daily oral hygiene procedures, especially in individuals with periodontitis who harbor high levels of periodontal pathogens [18]. Importantly, P. gingivalis carriage in the oral cavity is correlated with pancreatic cancer risk even when present years prior to pancreatic cancer diagnosis [4], consistent with the notion that migration of $P$. gingivalis to the pancreas from the oral cavity, even if transient and intermittent, increases cancer risk.

Despite the epidemiological evidence implicating P. gingivalis in pancreatic tumorigenesis [19], the direct effects of this bacterium on PDAC tumor progression have not been investigated, and the mechanisms underlying the $P$. gingivalis-PDAC link remain unclear. Here, we provide the first evidence that $P$. gingivalis exerts direct pro-tumorigenic effects on pancreatic cancer cells. Although PDAC cells are reported to express some Toll-like receptors [20], and P. gingivalis induces proliferation of oral epithelial tumor cells in a TLR2-dependent manner [21], we found that pancreatic tumor cell proliferation is enhanced by $P$. gingivalis independently of TLR2. Since $P$. gingivalis is known to invade and persist in epithelial cells [22,23], we next addressed the hypothesis that $P$. gingivalis intracellular survival is linked to its ability to promote pancreatic tumor cell proliferation. Importantly, we found that hypoxia, a dominant feature of the PDAC microenvironment [24,25], greatly enhances $P$. gingivalis intracellular survival. To the best of our knowledge, our study is the first to test the mechanistic involvement of $P$. gingivalis in pancreatic tumorigenesis, applying in vitro tools and a xenograft pancreatic carcinoma model in vivo. Our results reveal a previously unknown direct effect of $P$. gingivalis on PDAC progression, highlighting the importance of the interplay between hypoxia and $P$. gingivalis intracellular survival in this process.

\section{Results}

\subsection{P. gingivalis Infection Enhances Pancreatic Tumor Cell Proliferation}

To investigate how P. gingivalis influences PDAC progression, we first compared the proliferation of pancreatic carcinoma cell lines in the absence or presence of $P$. gingivalis. As shown in Figure 1 , $P$. gingivalis infection significantly increased the proliferation rate of the human PDAC cell lines PANC1 and MIA PaCa-2, and the mouse cell line Panc02.
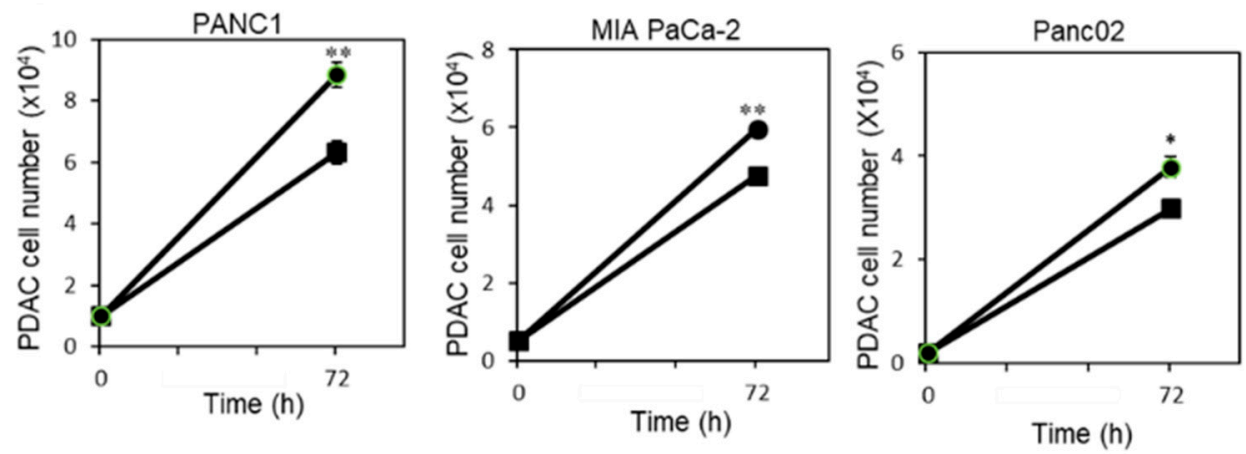

Figure 1. P. gingivalis infection enhances PDAC cell proliferation. PDAC cells (PANC1, MIA PaCa-2, and Panc02) were cultured in the absence of antibiotics alone or in the presence of $P$. gingivalis (MOI 10 bacteria per cell, 4 wells per condition) and cell number was calculated at the indicated time points (squares indicate cells without bacteria, and circles indicate cells with bacteria). One representative experiment of three is shown. Two-tailed $t$-test was performed for statistical analysis. ${ }^{*} p \leq 0.05$, ** $p \leq 0.01$. 
P. gingivalis was previously shown to promote growth of cancer cells (of non-pancreatic origin, i.e., oral squamous cell carcinoma) through a TLR2 dependent mechanism [21]. Therefore, we next hypothesized that TLR2 is involved in mediating increased proliferation of PDAC cells in the presence of $P$. gingivalis. However, blocking TLR2 with a TLR2-neutralizing antibody (clone T2.5, [6]) did not diminish the P. gingivalis-induced proliferation of PDAC cells (Figure S1 (Supplementary Materials)). Moreover, RT-PCR analysis showed that PDAC cell lines used in our experiments do not express TLR2, in line with previous reports [26]. Accordingly, we were unable to detect induction of inflammatory cytokines typically associated with TLR2 activation in the PDAC cell lines following exposure to $P$. gingivalis (e.g., IL-6 and TNF $\alpha$ ), further confirming that the growth-promoting effects of $P$. gingivalis on pancreatic carcinoma cells are not mediated by TLR2.

\subsection{Enhanced Tumor Cell Proliferation Correlates with P. gingivalis Intracellular Survival}

P. gingivalis is known to survive and even multiply within gingival epithelial cells $[23,27]$. We next hypothesized that proliferation induced by $P$. gingivalis is a consequence of intracellular survival. To study intracellular survival, we infected pancreatic cancer cells for $1 \mathrm{~h}$, washed and treated the cells with antibiotics to kill extracellular bacteria, and then incubated the cells for extended periods of time. Under these conditions, no live bacteria were recoverable from the culture media collected after antibiotic treatment, in the presence or absence of the cancer cells. We recovered live organisms from within pancreatic cancer cells two days after infection; however, no live bacteria were recovered 3 days after infection (Figure 2). Incubation of pancreatic cancer cells in 1\% oxygen to mimic the hypoxic conditions of pancreatic tumors greatly increased $P$. gingivalis intracellular survival and persistence, demonstrated by the difference in the number of colonies recovered at $48 \mathrm{~h}$ in the different conditions, and the fact that live $P$. gingivalis was recovered from the cancer cells grown for $72 \mathrm{~h}$ in hypoxic conditions, but not from those cells infected with the same $P$. gingivalis and then grown in normoxic conditions (Figure 2). Therefore, P. gingivalis is slowly cleared from inside PDAC cells in a manner related to environmental oxygen levels.

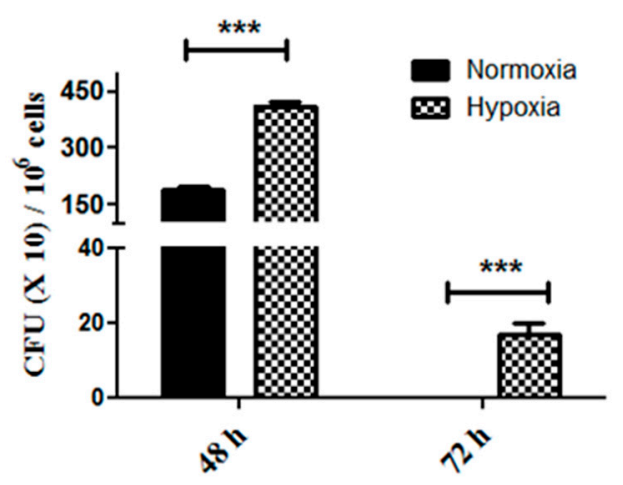

Figure 2. P. gingivalis intracellular survival assay. PANC1 cells were infected with $P$. gingivalis for $1 \mathrm{~h}$ in normoxic vs. hypoxic conditions and treated with antibiotics to remove all extracellular bacteria. Cells were lysed at the indicated time points, and lysates were plated on anaerobic blood agar plates to determine CFU. The experiment was performed three times. Data show the mean $\pm \mathrm{SD}$ of a representative experiment $(n=3)$. Two-tailed $t$-test was performed for statistical analysis. ${ }^{* * *} p \leq 0.005$.

To explore the relationship between intracellular survival and the effect of $P$. gingivalis on proliferation, we endeavored to enhance the intracellular survival of $P$. gingivalis strain 381 by successive rounds of infection in either normoxia or hypoxia. For PANC1 cells grown in normoxia, a single $P$. gingivalis colony recovered from inside cells that were lysed at $48 \mathrm{~h}$ was expanded and used to infect cells in the next round. After four rounds of infection, we were now able to recover $P$. gingivalis from cells grown for $72 \mathrm{~h}$ in normoxic conditions, and the number of intracellular $P$. gingivalis colonies continued to increase with successive rounds of infection (Figure 3a). For hypoxic conditions, a single 
P. gingivalis colony recovered from inside cells that were lysed at $72 \mathrm{~h}$ was expanded and used to infect cells in the next round. Six rounds of infection (each time using a colony recovered from PANC1 cells grown for $72 \mathrm{~h}$ to re-infect fresh PANC1 cells) increased the number of intracellular $P$. gingivalis colonies recovered at $72 \mathrm{~h}$ in hypoxic conditions greater than 20 -fold (Figure $3 \mathrm{~b}$ ). To confirm that the bacteria were adapted to intracellular survival rather than enhanced invasiveness, we infected fresh PANC1 cells for $1 \mathrm{~h}$ with the original laboratory stock of $P$. gingivalis ("oPG") vs. a P. gingivalis stock based on bacteria that had been enhanced for intracellular survival by six successive rounds of infection and recovery from inside the PANC1 cells (we refer to this as "ePG"). The PANC1 cells were treated with antibiotics to eliminate extracellular bacteria, and then cells were immediately lysed with water to recover the intracellular bacteria (" $0 \mathrm{~h}$ "), vs. incubation for $72 \mathrm{~h}$ and then lysis. As expected, there were large differences in the number of CFU recovered at $72 \mathrm{~h}$, however there were no differences in the number of bacteria recovered immediately after infection (the $0 \mathrm{~h}$ time point), demonstrating that the bacteria (oPG vs. ePG) entered the cells to the same degree but differed in their ability to persist inside the cells (Figure 3c,d). Consistent with the intracellular survival, fluorescently-labeled ePG was detected by confocal microscopy in both PANC1 and MIA PaCa-2 cells (Figure 3e,f).
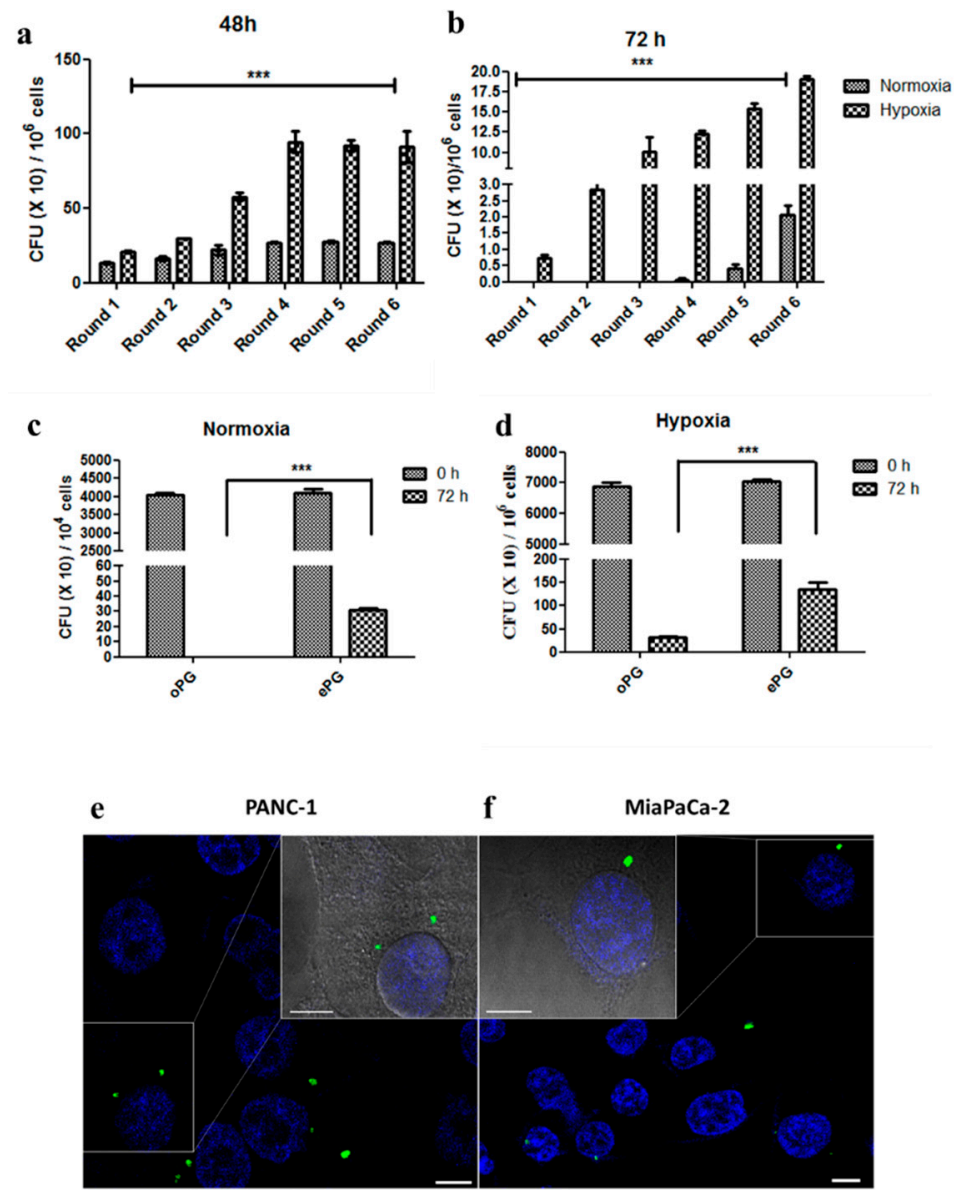

Figure 3. $P$. gingivalis intracellular survival in PDAC cells can be enhanced in vitro. (a,b) Intracellular P. gingivalis CFU recovered $48 \mathrm{~h}$ and $72 \mathrm{~h}$ after infection. (c,d) Intracellular "original" vs. "enhanced" $P$. gingivalis (see text for explanation) recovered immediately after antibiotic treatment $(0 \mathrm{~h})$ or after $72 \mathrm{~h}$ in normoxic or hypoxic conditions. Experiment was performed three times. Data show the mean \pm SD of a representative experiment ( $n=2$ wells per condition). Two-way ANOVA was performed for statistical analysis. ${ }^{* * *} p \leq 0.005$. (e,f) FITC-labeled $P$. gingivalis was used to infect PANC1 or Mia Paca- 2 cells. After $24 \mathrm{~h}$ infection, cells were fixed and nuclei were stained with DAPI prior to visualization using a NIKON confocal microscope at $60 \times$ magnification. One cell is magnified and shown with brightfield overlay for each image. The experiment was performed twice. 
We next compared the effect of oPG vs. ePG on the proliferation of PANC1 cells, in either normoxia or hypoxia. In both conditions, P. gingivalis adapted for intracellular survival enhanced proliferation significantly more than the original stock of bacteria (Figure 4a,b). Exposure to heat-killed ePG did not increase cell proliferation, demonstrating that live bacteria are required to enhance proliferation (Figure 4c, similar results obtained for oPG).

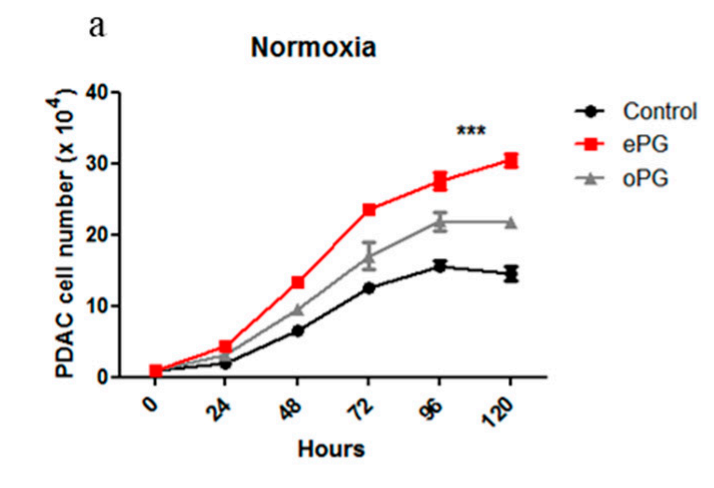

b
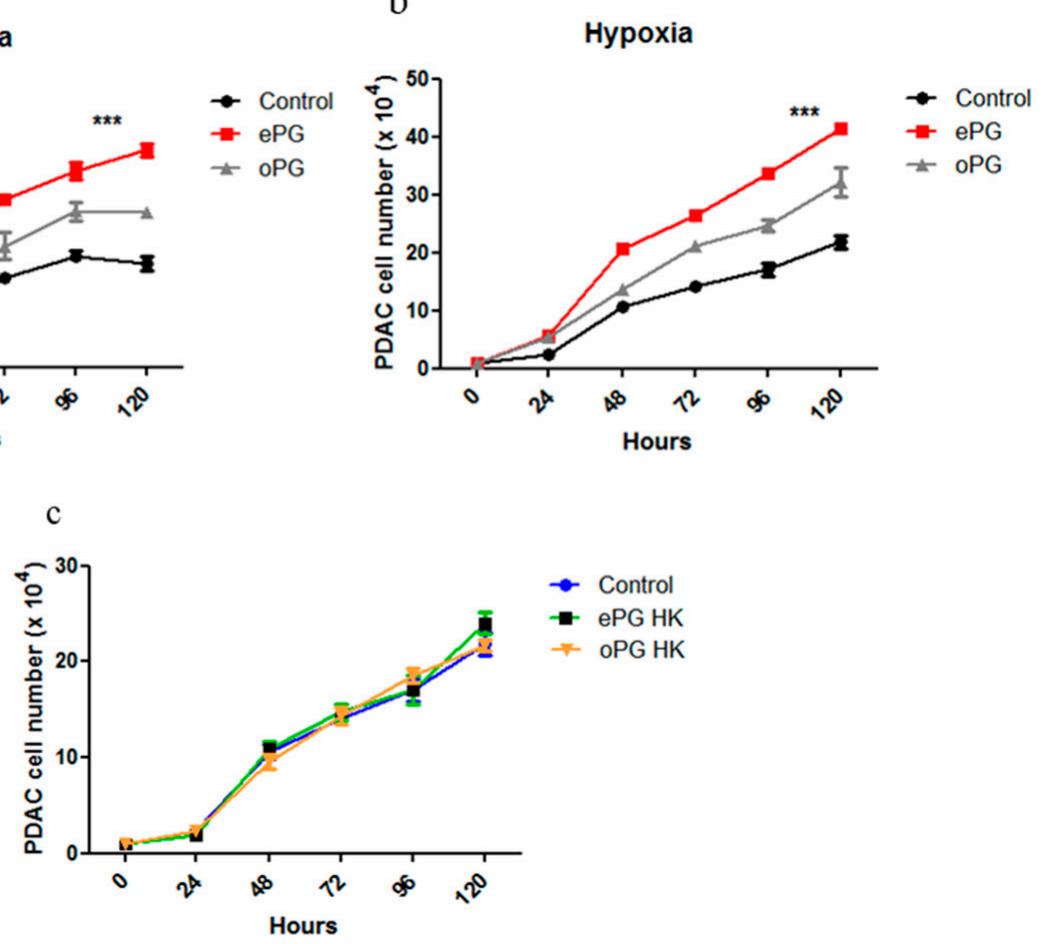

Figure 4. Enhanced P. gingivalis intracellular survival correlates with increased PDAC proliferation. (a) PANC1 cells were cultured in normoxia or (b) hypoxia alone or in the presence of oPG vs. ePG (MOI 10). For each of the conditions (normoxia vs. hypoxia), the ePG generated in those conditions was used. Extracellular bacteria were killed with antibiotics after one hour of infection, and cell number was calculated at the indicated time points. (c) Cells were cultured in hypoxic conditions alone (control) or in the presence of heat-killed (HK) ePG or oPG, and cell number was determined at the indicated time points. Experiment was performed three times. Data show the mean \pm SD of a representative experiment $(n=3)$. Two-way ANOVA was performed for statistical analysis. ${ }^{* * *} p \leq 0.005$.

The enhanced proliferation induced by ePG was confirmed in three PDAC cell lines at four and six days after infection using an additional test of cell viability (Figure 5a-c). In agreement with increased proliferation, we also found that $P$. gingivalis-infected cells had elevated levels of cyclin D1, an important regulator of proliferation/cell cycle progression in a variety of tumor types, including PDAC (Figure S2 (Supplementary Materials)) [28]. In addition, we noted that $P$. gingivalis infection resulted in increased levels of heparanase, an enzyme involved in PDAC tumor growth and aggressiveness (Figure S2 (Supplementary Materials)) [29,30]. 
a

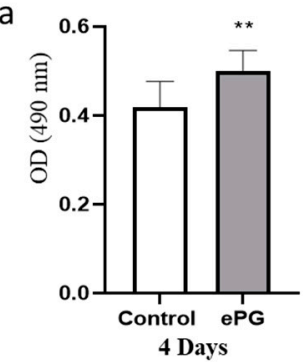

b

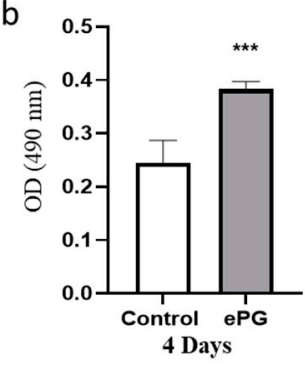

C

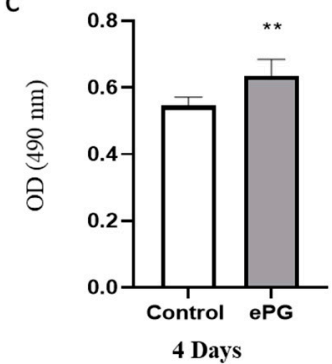

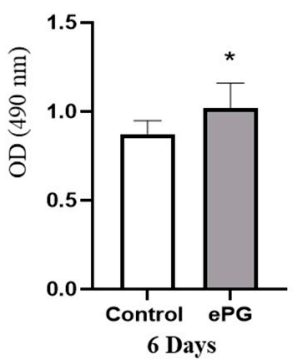
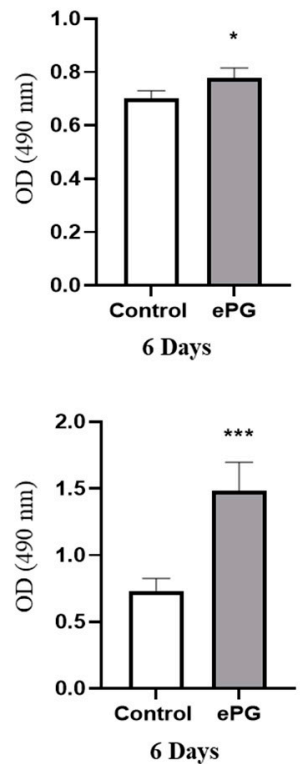

Figure 5. Enhanced proliferation induced by ePG in three human PDAC cell lines. (a) PANC1 cells, (b) MIA PaCa-2, and (c) BxPC-3 cells were cultured in hypoxia alone or with ePG (MOI 10). Extracellular bacteria were killed with antibiotics after one hour of infection, and cell proliferation was determined by MTS after 4 or 6 days. Two-tailed $t$-test was performed for statistical analysis. ${ }^{*} p \leq 0.05,{ }^{*} p \leq 0.01$, $* * * x \leq 0.005$.

\subsection{P. gingivalis Enhances Tumor Growth and Akt Activation}

To investigate whether P. gingivalis influences pancreatic tumor growth in vivo, we injected severe combined immunodeficient (SCID) mice subcutaneously with PANC1 cells that were infected with ePG prior to injection, and control mice were injected with uninfected PANC1 cells. Cells were not treated with antibiotics due to a concern that antibiotic treatment would interfere with tumor engraftment; however, cells were extensively washed, and no live $P$. gingivalis was recovered from the extracellular medium prior to implantation. All mice injected with P. gingivalis-infected PANC1 cells $(n=7)$ developed xenograft tumors vs. six of seven mice injected with uninfected PANC1 cells. Consistent with the in vitro results, xenograft tumors formed by P. gingivalis-infected PANC1 cells were significantly larger than tumors formed by control cells (Figure 6a). P. gingivalis DNA was still detectable in tumor tissue at the time of sacrifice (Figure 6b), and small numbers of $P$. gingivalis were visible by fluorescence in-situ hybridization [31] 11 weeks after implantation (Figure 6c). As P. gingivalis has previously been shown to induce PI3K/Akt signaling in host cells of non-cancerous origin (i.e., gingival epithelial cells [32,33]), and given the key role of the PI3K/Akt pathway in PDAC progression [34], we next examined Akt signaling in the two groups of tumors. Akt signaling was strongly upregulated in tumors derived from $P$. gingivalis-infected cells compared to control tumors as evident by increased phospho-Akt (pAkt) levels (Figure $6 \mathrm{~d}, \mathrm{e}$ ). These in vivo findings were in agreement with the in vitro induction of pAKT by P. gingivalis infection of the PDAC cell lines (Figure S3 (Supplementary Materials)). Of note, Akt phosphorylation was persistently induced by infection of PANC1 cells, and was still 
significantly elevated compared to baseline at $24 \mathrm{~h}$ post challenge, and a similar effect was observed by infection of an additional pancreatic cancer cell line, MIA PaCa-2 (Figure S4 (Supplementary Materials)). Collectively, these findings suggest that the pro-tumorigenic effects of $P$. gingivalis may be explained, in part, by activation of the Akt signaling cascade.

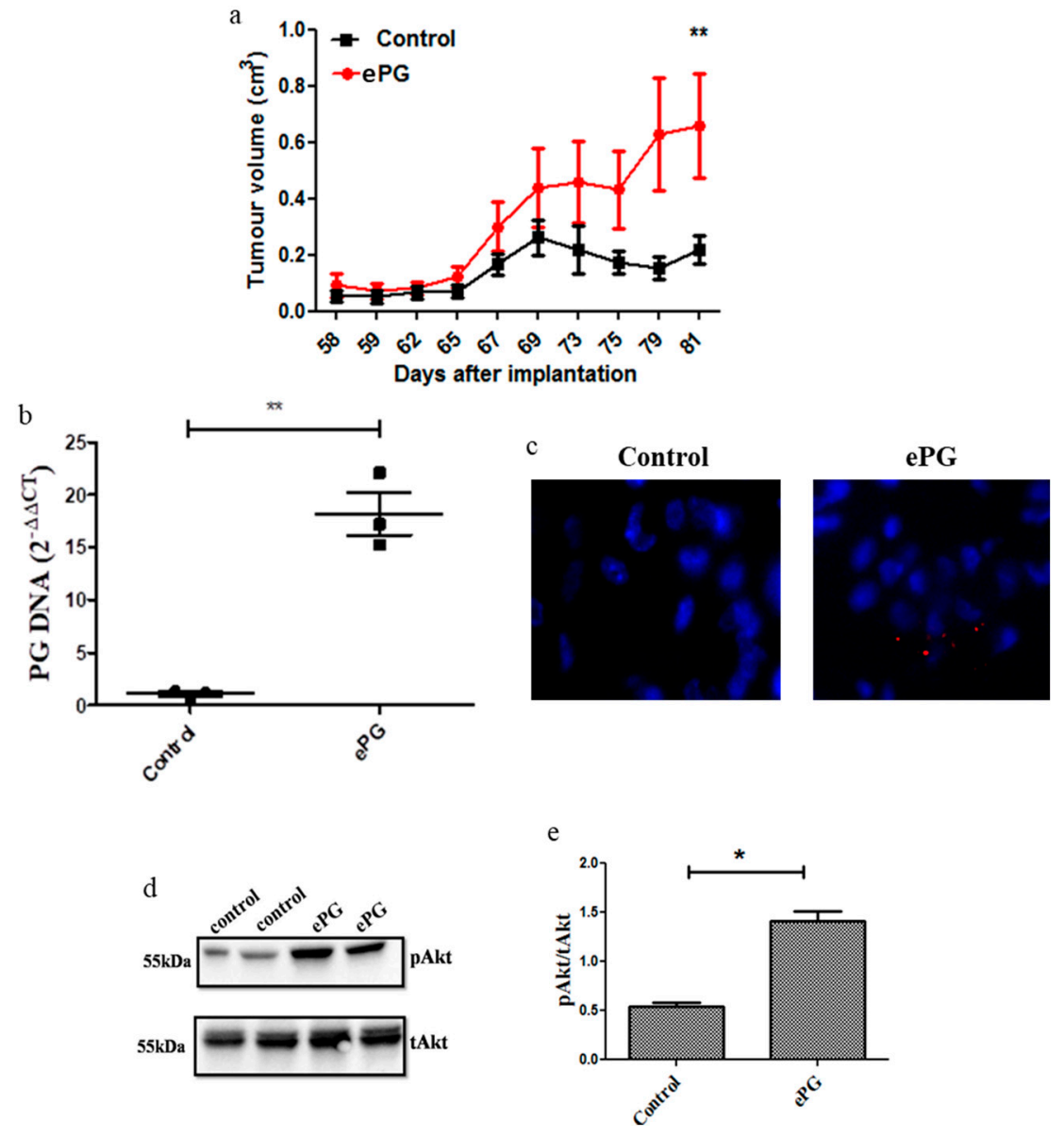

Figure 6. P. gingivalis enhances tumor growth and Akt phosphorylation. (a) PANC1 cells were incubated in hypoxia and infected with ePG or sham infected, and then injected subcutaneously to SCID mice ( $n=7$ per group). From the time tumors were palpable and through 11 weeks, tumor volume was monitored daily (in the control group one mouse did not develop a tumor and was not included in the analysis). (b) Following sacrifice on day 81 post implantation, tumors ( $n=3$ per group) were frozen and DNA was extracted as per the methods. RT PCR was performed using primers for the $16 \mathrm{~s}$ $P$. gingivalis rDNA gene and the human $18 \mathrm{~S}$ gene. Relative expression was calculated using the 2- $\Delta \Delta \mathrm{CT}$ method. ${ }^{* *} p=0.0011$. (c) For each group, three tumors were fixed in $4 \%$ paraformaldehyde and then embedded in OCT. Frozen sections were stained with a Cy3-labeled oligonucleotide specific for the P. gingivalis 16s rRNA gene (red), and nuclei were counterstained with DAPI (blue). Representative images of one control and one $P$. gingivalis-infected tumor at $20 \times$ magnification are shown. (d,e) Tumor protein lysates from two mice in each group were analyzed by Western blot for Akt phosphorylation (d) and protein levels were determined by densitometry (e). ${ }^{*} p \leq 0.05,{ }^{* *} p \leq 0.01$.

\section{Discussion}

The prognosis of pancreatic ductal adenocarcinoma is dismal, and most cases are diagnosed at late stages of disease in individuals without known risk factors [35]. Therefore, there is an urgent need to identify new, modifiable risk factors that contribute to tumor development and aggressiveness. Prospective epidemiologic studies have linked the periodontal bacterium P. gingivalis to pancreatic cancer [4,5]; however, functional studies that explain this link are lacking. In this study, we demonstrated 
that $P$. gingivalis directly affects PDAC cells. $P$. gingivalis induces PDAC cell proliferation, which is enhanced in hypoxic conditions (characteristic for pancreatic carcinoma [24]). Promotion of proliferation is linked to the intracellular survival of the bacteria (Figure 3) and its ability to augment Akt signaling and cyclin D1 expression (Figure 6 and Figures S2-S4 (Supplementary Materials)), one of the crucial pathways implicated in PDAC progression [28,34].

TLR2 plays a major role in the host response to $P$. gingivalis; however, the bacteria manipulate TLR2 signaling in immune cells to evade bactericidal activity while inducing inflammation $[6,7,36]$. P. gingivalis also promotes proliferation of oral carcinoma cells in a TLR2-dependent manner [21]. Nevertheless, here we show that in the setting of pancreatic cancer, tumor-promoting effects of $P$. gingivalis are TLR2-independent, and enhanced by increasing the ability of bacteria to survive within the cells. Intracellular $P$. gingivalis survival is a well-known phenomenon in gingival epithelial cells [37], and $P$. gingivalis has been shown to multiply and even spread between gingival epithelial cells during the first day after infection, although over time, in culture, $P$. gingivalis persistence in gingival epithelial cells decreases [27,38]. Intracellular survival in cancer cells is a novel mechanism whereby bacteria may influence cancer development. Bacterial adaptation to intracellular life in cancer cells, and the kinetics of intracellular persistence, may differ from infection of gingival epithelial cells $[23,27,37]$. We found that hypoxia further increases $P$. gingivalis intracellular survival and the proliferation of PDAC cells. In contrast, hypoxia upregulates the bactericidal activity of keratinocytes against Gram-positive bacteria [39]. Since hypoxia is a prominent feature of pancreatic tumors [24], and an important determinant of PDAC malignancy [24,25], pancreatic tumors may be an ideal niche for $P$. gingivalis intracellular survival. Our findings provide the first evidence for a direct effect of intracellular $P$. gingivalis on activation of cancer signaling pathways (evidenced by prolonged Akt phosphorylation in vitro, and in the xenograft tumors); however, the full spectrum of cancer properties affected by $P$. gingivalis infection in PDAC, and the precise molecular mechanisms underlying the effects have still to be determined. For example, in healthy epithelial cells, $P$. gingivalis or its surface components have been shown to both induce and inhibit expression of apoptotic factors and cellular apoptosis [40-44]. Our ongoing studies are focused on how intracellular P. gingivalis affects the PDAC apoptosis machinery, especially since BCL2, a powerful anti-apoptotic factor whose expression correlates with apoptotic resistance and metastatic potential in PDAC [45], can either be increased or inhibited by $P$. gingivalis $[43,44]$. One intriguing possibility is that intracellular $P$. gingivalis may influence tumor development by synergizing with other oncogenic factors that upregulate the same pathways, such as mutant KRAS, the hallmark genetic mutation of PDAC [46]. In the context of PDAC development, it is important to explore the potential synergy between intratumoral bacteria and oncogenic signaling pathways.

P. gingivalis strains available from the ATCC were isolated from humans with periodontitis decades ago, and have been passaged enumerable times in culture which may lead to loss of virulence. Furthermore, virulence mechanisms, including intracellular survival, vary among available laboratory strains [47], suggesting that clinical isolates may differ in their ability to persist in cancer cells. Starting with the laboratory strain P. gingivalis 381 isolated by Tanner in 1979 [48], we demonstrated that intracellular persistence can be enhanced in vitro, suggesting that it may occur in vivo as well. It will be critical to determine the changes bacteria undergo to adapt to intracellular life in cancer cells, and if clinical isolates of $P$. gingivalis differ in their potential to influence pancreatic tumorigenesis.

A convergence of human and mouse studies demonstrate that oral cavity and intestinal microbes (including P. gingivalis) can colonize the healthy and tumor-containing pancreas $[12,14-17,49,50]$. $P$. gingivalis is a member of the phylum Bacteroidetes, which was among the most abundant phyla in human PDAC samples in one study [15], although it was much less abundant in other studies [14,16]. Quantitative assessment of the pancreatic microbiota at a single time point may be inadequate to reveal a role for particular microbes in cancer progression. The prospective study by Fan et al. correlated salivary $P$. gingivalis with pancreatic cancer risk even when at least two years separated the two events [4]. Therefore, $P$. gingivalis can be a transient traveler to the pancreas during the critical time 
course of PDAC maturation, even if it is not a significant member of the pancreatic microbiota at the time of diagnosis. Although a limitation of the present study is that a single model was used for in vivo confirmation, our report on a new role of intracellular P. gingivalis in PDAC may help to disentangle the enormous complexity of the PDAC-periodontitis link.

\section{Materials and Methods}

\subsection{Bacteria and Growth Conditions}

P. gingivalis strain 381 or 33,277 were cultured in Wilkins broth (Oxoid, Basingstoke, UK) under anaerobic conditions $\left(85 \% \mathrm{~N}_{2}, 5 \% \mathrm{H}_{2}\right.$ and $\left.10 \% \mathrm{CO}_{2}\right)$ in AnaeroJar ${ }^{\mathrm{TM}}$ at $37^{\circ} \mathrm{C}$. Optical density at $650 \mathrm{~nm}$ of 0.1 was determined to be equivalent to $10^{10}$ bacterial counts per mL.

\subsection{Cell Lines and Culture Conditions}

Human pancreatic carcinoma cell lines MIA PaCa-2 and PANC1 (authenticated by STR profiling at the Genomics Center of the Biomedical Core Facility, Technion University, Haifa, Israel), and the mouse pancreatic carcinoma cell line Panc02 [51] were maintained in DMEM (Sigma-Aldrich, Rehovot, Israel) supplemented with $10 \%$ fetal calf serum, $2 \mathrm{mM} \mathrm{L-glutamine,} \mathrm{penicillin} \mathrm{(100} \mathrm{units} / \mathrm{mL}$ ), and streptomycin $\left(100 \mu \mathrm{g} / \mathrm{mL}\right.$; Biological Industries, Beit Haemek, Israel). The cells were cultured at $37^{\circ} \mathrm{C}$ and $5 \% \mathrm{CO}_{2}$ (normoxia). To induce a hypoxic environment, cells were cultured at $37^{\circ} \mathrm{C}$ in a Hypoxia Incubator Chamber (STEMCELL Technologies, Vancouver, BC, Canada) flushed with a gas mixture of $5 \% \mathrm{CO}_{2} /$ $94 \% \mathrm{~N}_{2} / 1 \% \mathrm{O}_{2}$ for $4 \mathrm{~h}$ prior to infection with $P$. gingivalis.

\subsection{Cell Proliferation Assay}

Cells were plated in 24-well plates at $10^{4}$ cells per well in DMEM. One hour prior to bacterial infection, the medium was changed to DMEM without antibiotics and cells were incubated with P. gingivalis (MOI 10), or left untreated. Cell numbers were counted the indicated time intervals using a hemocytometer. Alternatively, cell proliferation was measured using the Promega CellTiter $96^{\circledR}$ AQueous One Solution Cell Proliferation Assay (MTS, Cat No. G5430, Promega, city, Madison, WI, USA). We plated 1000-2000 pancreatic cancer cells/well in 96 well plates, and the cells were incubated in hypoxia for $4 \mathrm{~h}$ before infection with $P$. gingivalis MOI 10 for $1 \mathrm{~h}$. Cells were then washed, treated with metronidazole and gemtamycin for $1 \mathrm{~h}$, and incubated for 4 or 6 days in hypoxia. MTS solution $(20 \mu \mathrm{L})$ was added to each well and incubated at $37^{\circ} \mathrm{C}$ for $1.5 \mathrm{~h}$. The absorbance at $490 \mathrm{~nm}$ was used to evaluate cell proliferation.

\subsection{P. gingivalis Intracellular Survival Assay (ICS)}

Approximately 0.8 to $1 \times 10^{6}$ PANC1 cells per well were plated in 6-well plates and infected with P. gingivalis at multiplicity of infection (MOI) 10 in duplicate or triplicate for $1 \mathrm{~h}$ in either normoxic, or hypoxic conditions in the absence of antibiotics. For hypoxia, cells were pre-incubated in hypoxic conditions for $4 \mathrm{~h}$, and then infection and subsequent steps were performed in hypoxic conditions. For both normoxic and hypoxic conditions, cells were washed twice after infection, and then treated with metronidazole $(0.22 \mathrm{mg} / \mathrm{mL})$ and gentamycin $(0.3 \mathrm{mg} / \mathrm{mL})$ for an hour to eradicate all remaining extracellular adherent bacteria. After this treatment, cells were washed twice and incubated in full medium (as above, i.e., supplemented with penicillin and streptomycin, but without metronidazole and gentamicin) for 24,48 and $72 \mathrm{~h}$ in either normoxia or hypoxia. Cells were then lysed by treating with ice-cold distilled water for $20 \mathrm{~min}$. Serial dilutions of cell lysates were plated on anaerobic blood agar plates (Novamed, Jerusalem, Israel), and incubated under anaerobic conditions for a week to determine the colony forming units (CFU) in each condition. To enhance $P$. gingivalis intracellular survival, one $P$. gingivalis colony recovered in each condition (normoxia vs. hypoxia) was expanded in liquid medium, and then used to infect fresh PANC1 cells. This was performed successively, and each infection-recovery cycle is referred to as a "round" of infection. 


\subsection{Detection of Intracellular P. gingivalis}

We plated 30,000 cells/well in IBIDI chamber slides (Ibidi, Martinsried, Germany), and incubated in hypoxia for $4 \mathrm{~h}$ prior to infection with FITC-labeled P. gingivalis MOI 10 for $1 \mathrm{~h}$. P. gingivalis was labeled with $0.1 \mathrm{mg} / \mathrm{mL}$ FITC (Sigma) in carbonate buffer ( $\mathrm{pH}$ 9.5) for $20 \mathrm{~min}$ at RT and then extensively washed in PBS. Infection and all subsequent steps were carried out in hypoxia. Following infection, cells were washed, treated with metronidazole and gentamicin for $1 \mathrm{~h}$, washed, and incubated for $24 \mathrm{~h}$. The wells were then fixed with $2 \%$ formaldehyde for $15 \mathrm{~min}$ and blocked with $0.1 \%$ Triton $/ 2 \%$ BSA. Nuclei were stained with DAPI $3 \mu \mathrm{L} / \mathrm{mL}$ blocking solution for $30 \mathrm{~m}$. Cells were washed twice, and then IBIDI mounting medium was applied. Multi-projection images were obtained using a NIKON confocal fluorescent microscope at $60 \times$ magnification.

\subsection{Analysis of Gene Expression by qRT-PCR}

Total RNA was isolated from PANC-1 cells using TRIzol (Invitrogen, Thermo Fisher Scientific, Madison, WI, USA), according to the manufacturer's instructions, and quantified by spectrophotometry (NanoDrop One, Thermo Fisher Scientific). After oligo (dT)-primed reverse transcription of $1 \mu \mathrm{g}$ total RNA, the resulting single stranded cDNA was amplified using the primers listed below. Real-time quantitative PCR (qRT-PCR) analysis was performed on a BioRad CFX Connect system (Bio-Rad, Hercules, CA, USA). The PCR reaction mix $(10 \mu \mathrm{L})$ was composed of $5 \mu \mathrm{L}$ QPCR sybr master mix (Bio-Rad), $1 \mu \mathrm{L}$ cDNA, and a final concentration of $0.5 \mu \mathrm{M}$ of each primer diluted in ultra-pure water. Glyceraldehyde 3-phosphate dehydrogenase (GAPDH) was used as an internal control for normalization. The following primers were utilized: Human GAPDH F: 5'-TCCACTGGGGTCTTGACG-3', R: 5'-GGCAGAGATGATGACCCTTTT-3' . Human Cyclin D1 F: 5'-TGTTCGTGGCCTCTAAGATGAAG-3', R: 5'-AGGTTCCACTTGAGCTTGTTCAC-3' . Human Heparanase F: 5'-GTTCTAATGCTCAGTTGCTCCT-3' , R: 5' -ACTGCGACCCATTGATGAAA-3' .

\subsection{Tumor Growth In Vivo}

Ten to twelve-week-old SCID mice were obtained from Envigo (Jerusalem, Israel) and housed in the Specific Pathogen-Free (SPF) facility of the Hebrew University. PANC1 cells were incubated in hypoxic conditions for four hours prior to infection with $P$. gingivalis enriched for intracellular survival (MOI of 10) vs. sham infection for one hour in hypoxia. Cells were washed three times and five million cells in $200 \mu \mathrm{L}$ PBS per mouse were implanted into the subcutaneous space of the flank $(n=7)$. Mice were monitored daily and tumor length and width was calculated using a caliper from the first day that the tumor was palpable. Tumor volumes based on caliper measurements were calculated by the modified ellipsoidal formula (tumor volume $=\left(\right.$ length $\times$ width $\left.{ }^{2}\right) / 2$ ). Animal experiments were approved by the Institutional Animal Care and Use Committee using protocol MD-13-12544.

\subsection{Detection of P. gingivalis in Tumor Tissue}

Intact tumor tissue was isolated from mice at the end of the experiment (day 81) and DNA from tumor samples was isolated using Qiagen DNeasy kit (Qiagen, Hilden, Germany). P. gingivalis DNA was identified in host tumor tissue by RT PCR (BioRad, Haifa, Israel) using specific qPCR primers for the $P$. gingivalis $16 \mathrm{~S}$ gene [6], forward sequence $5^{\prime}$-AGAGTTTGATCCTGCTCAG-3' and reverse sequence $5^{\prime}$-CAATACTCGTATCGCCCGTTATTC-3'. The human $18 \mathrm{~S}$ rRNA gene was used as an internal control for DNA extraction from the tumor tissue, forward sequence: $5^{\prime}$ - CTACCACATCCAAGGAAGCA-3', and reverse sequence: $5^{\prime}$ - TTTTTCGTCACTACCTCCCCG $-3^{\prime}$. The expression of $P$. gingivalis DNA in the tumor tissue relative to human DNA was calculated using the delta-delta $C t$ method $\left(2^{-\Delta \Delta C t}\right)$.

\subsection{Fluorescence In Situ Hybridization (FISH)}

Excised tumor tissue was fixed overnight in $4 \%$ paraformaldehyde (Sigma) and embedded in Cryostat Embedding Medium (OCT, Fisher Scientific, Waltham, MA, USA), and frozen in liquid 
nitrogen. Frozen blocks were cryosectioned at $10 \mu \mathrm{m}$ for FISH. Sections were washed in 99.5\% ethanol and probed with $5 \mathrm{mg} / \mathrm{mL}$ of $P$. gingivalis $16 \mathrm{~s}$ rRNA- specific oligonucleotide POGI 5'-CAA TAC TCG TAT CGC CCG TTA TTC-3' (as per [31]) labeled with Cy3 dye (Hy-Labs, Rehovot, Israel) in hybridization solution $(0.9 \mathrm{mM} \mathrm{NaCl}, 20 \mathrm{mM}$ Tris/HCl, pH 7.3, and 0.01\% SDS). Slides were incubated in a humid chamber at $46{ }^{\circ} \mathrm{C}$ for $3.5 \mathrm{~h}$ in the dark. Slides were then rinsed in sterile double distilled water, air dried, and counter stained with $1 \mu \mathrm{L} / \mathrm{mL}$ DAPI (Sigma-Aldrich). Slides were visualized using a NIKON eclipse $80 \mathrm{i}$ fluorescent microscope at $20 \times$ magnification.

\subsection{Western Blot}

Tumor tissue or P. gingivalis infected cells were lysed in RIPA lysis buffer containing protease and phosphatase inhibitors, and protein concentration was measured by Bradford (Bio-Rad, Hercules, CA, USA). Proteins were separated by SDS-PAGE and transferred to nitrocellulose membranes. Rabbit antibodies were from Cell Signaling (Cell Signaling, Danvers, MA, USA): anti-phospho-AKT (clone D9E), and anti-Akt (pan, clone C67E7). Primary rabbit antibodies were used at $2 \mu \mathrm{g} / \mathrm{mL}$ overnight, followed by secondary goat anti-rabbit IgG-HRP (Abcam, Cambridge, UK). ECL-chemiluminescence detection kit (Biological Industries) was used to detect the proteins, and images were captured using a Bio-Rad imaging system (Bio-Rad, Hercules, CA, USA). Total and phosphor-AKT levels were determined by densitometry. Detailed information about western blot can be found at Figures S5-S7 (Supplementary Materials).

\subsection{Statistical Analysis}

Significant differences between the means were analyzed using the unpaired Student's $t$ test or the two-way ANOVA (Prism v.8, GraphPad Software Inc., San Diego, CA, USA). A $p$ value $<0.05$ was considered statistically significant.

\section{Conclusions}

Our findings, taken together with the previously published prospective epidemiologic studies, lead us to conclude that the periodontal bacterium $P$. gingivalis may act as a mechanistic determinant in pancreatic carcinoma progression. Moreover, our observations highlight the importance of the interplay between hypoxia (a characteristic feature of PDAC tumors) and P. gingivalis intracellular survival in pancreatic carcinoma cells.

Supplementary Materials: The following are available online at http://www.mdpi.com/2072-6694/12/8/2331/s1, Figure S1: Pancreatic cancer cell proliferation induced by $P$. gingivalis is independent of TLR2, Figure S2: Increased expression of Cyclin-D1 and Heparanase in PANC-1 cells infected with P. gingivalis, Figure S3: P. gingivalis induces sustained phospho-Akt in PANC1 cells, Figure S4: P. gingivalis enhances Akt phosphorylation in MIA PaCa-2 cells, Figure S5: Detailed information about Figure 6d, Figure S6: Full length gels and densitometry readings for Figure S3, Figure S7: Full length gels and densitometry readings for Figure S4.

Author Contributions: Conceptualization, J.G., M.E. and G.N.; methodology, data acquisition and interpretation, statistical analyses, J.G., A.B.G., E.S., K.P., L.E.B., E.H., S.A., H.M., A.K., A.D., M.E. and G.N.; writing, review, and editing, J.G., M.E. and G.N.; supervision, M.E. and G.N. All authors have read and agree to the published version of the manuscript.

Funding: This research was funded by a grant from the Israel Science Foundation awarded to G.N., grant number 1391/17, a grant from the Israel Science Foundation grant number 1715/17 awarded to M.E. and a grant from the Legacy Heritage Bio-Medical Program number 663/16 awarded to M.E.

Conflicts of Interest: The authors declare no conflict of interest. The funders had no role in the design of the study; in the collection, analyses, or interpretation of data; in the writing of the manuscript, or in the decision to publish the results. 


\section{References}

1. Regel, I.; Mayerle, J.; Mahajan, U.M. Current strategies and future perspectives for precision medicine in pancreatic cancer. Cancers 2020, 12, 24. [CrossRef] [PubMed]

2. Zheng, L.; Xue, J.; Jaffee, E.M.; Habtezion, A. Role of immune cells and immune-based therapies in pancreatitis and pancreatic ductal adenocarcinoma. Gastroenterology 2013, 144, 1230-1240. [CrossRef] [PubMed]

3. Ahn, J.; Segers, S.; Hayes, R.B. Periodontal disease, Porphyromonas gingivalis serum antibody levels and orodigestive cancer mortality. Carcinogenesis 2012, 33, 1055-1058. [CrossRef]

4. Fan, X.; Alekseyenko, A.V.; Wu, J.; Peters, B.A.; Jacobs, E.J.; Gapstur, S.M.; Purdue, M.P.; Abnet, C.C.; Stolzenberg-Solomon, R.; Miller, G.; et al. Human oral microbiome and prospective risk for pancreatic cancer: A population-based nested case-control study. Gut 2016. [CrossRef] [PubMed]

5. Michaud, D.S.; Izard, J.; Wilhelm-Benartzi, C.S.; You, D.H.; Grote, V.A.; Tjonneland, A.; Dahm, C.C.; Overvad, K.; Jenab, M.; Fedirko, V.; et al. Plasma antibodies to oral bacteria and risk of pancreatic cancer in a large European prospective cohort study. Gut 2013, 62, 1764-1770. [CrossRef] [PubMed]

6. Makkawi, H.; Hoch, S.; Burns, E.; Hosur, K.; Hajishengallis, G.; Kirschning, C.J.; Nussbaum, G. Porphyromonas gingivalis stimulates TLR2-PI3K signaling to escape immune clearance and induce bone resorption independently of MyD88. Front. Cell. Infect. Microbiol. 2017, 7, 359. [CrossRef]

7. Maekawa, T.; Krauss, J.L.; Abe, T.; Jotwani, R.; Triantafilou, M.; Triantafilou, K.; Hashim, A.; Hoch, S.; Curtis, M.A.; Nussbaum, G.; et al. Porphyromonas gingivalis manipulates complement and TLR signaling to uncouple bacterial clearance from inflammation and promote dysbiosis. Cell Host Microbe 2014, 15, 768-778. [CrossRef]

8. Olsen, I.; Progulske-Fox, A. Invasion of Porphyromonas gingivalis strains into vascular cells and tissue. J. Oral Microbiol. 2015, 7, 28788. [CrossRef]

9. Olsen, I.; Yilmaz, O. Possible role of Porphyromonas gingivalis in orodigestive cancers. J. Oral Microbiol. 2019, 11, 1563410. [CrossRef]

10. Ishikawa, M.; Yoshida, K.; Okamura, H.; Ochiai, K.; Takamura, H.; Fujiwara, N.; Ozaki, K. Oral Porphyromonas gingivalis translocates to the liver and regulates hepatic glycogen synthesis through the Akt/GSK-3beta signaling pathway. Biochim. Biophys. Acta 2013, 1832, 2035-2043. [CrossRef]

11. Katz, J.; Chegini, N.; Shiverick, K.T.; Lamont, R.J. Localization of P. gingivalis in preterm delivery placenta. J. Dent. Res. 2009, 88, 575-578. [CrossRef] [PubMed]

12. Ilievski, V.; Toth, P.T.; Valyi-Nagy, K.; Valyi-Nagy, T.; Green, S.J.; Marattil, R.S.; Aljewari, H.W.; Wicksteed, B.; O’Brien-Simpson, N.M.; Reynolds, E.C.; et al. Identification of a periodontal pathogen and bihormonal cells in pancreatic islets of humans and a mouse model of periodontitis. Sci. Rep. 2020, 10, 9976. [CrossRef] [PubMed]

13. Blasco-Baque, V.; Garidou, L.; Pomie, C.; Escoula, Q.; Loubieres, P.; Le Gall-David, S.; Lemaitre, M.; Nicolas, S.; Klopp, P.; Waget, A.; et al. Periodontitis induced by Porphyromonas gingivalis drives periodontal microbiota dysbiosis and insulin resistance via an impaired adaptive immune response. Gut 2017, 66, 872-885. [CrossRef] [PubMed]

14. Geller, L.T.; Barzily-Rokni, M.; Danino, T.; Jonas, O.H.; Shental, N.; Nejman, D.; Gavert, N.; Zwang, Y.; Cooper, Z.A.; Shee, K.; et al. Potential role of intratumor bacteria in mediating tumor resistance to the chemotherapeutic drug gemcitabine. Science 2017, 357, 1156-1160. [CrossRef]

15. Pushalkar, S.; Hundeyin, M.; Daley, D.; Zambirinis, C.P.; Kurz, E.; Mishra, A.; Mohan, N.; Aykut, B.; Usyk, M.; Torres, L.E.; et al. The pancreatic cancer microbiome promotes oncogenesis by induction of innate and adaptive immune suppression. Cancer Discov. 2018, 8, 403-416. [CrossRef]

16. Thomas, R.M.; Gharaibeh, R.Z.; Gauthier, J.; Beveridge, M.; Pope, J.L.; Guijarro, M.V.; Yu, Q.; He, Z.; Ohland, C.; Newsome, R.; et al. Intestinal microbiota enhances pancreatic carcinogenesis in preclinical models. Carcinogenesis 2018. [CrossRef]

17. Mitsuhashi, K.; Nosho, K.; Sukawa, Y.; Matsunaga, Y.; Ito, M.; Kurihara, H.; Kanno, S.; Igarashi, H.; Naito, T.; Adachi, Y.; et al. Association of Fusobacterium species in pancreatic cancer tissues with molecular features and prognosis. Oncotarget 2015, 6, 7209-7220. [CrossRef]

18. Ambrosio, N.; Marin, M.J.; Laguna, E.; Herrera, D.; Sanz, M.; Figuero, E. Detection and quantification of Porphyromonas gingivalis and Aggregatibacter actinomycetemcomitans in bacteremia induced by interdental brushing in periodontally healthy and periodontitis patients. Arch. Oral Biol. 2019, 98, 213-219. [CrossRef] 
19. Liu, X.B.; Gao, Z.Y.; Sun, C.T.; Wen, H.; Gao, B.; Li, S.B.; Tong, Q. The potential role of P.gingivalis in gastrointestinal cancer: A mini review. Infect. Agents Cancer 2019, 14, 23. [CrossRef]

20. Vaz, J.; Andersson, R. Intervention on toll-like receptors in pancreatic cancer. World J. Gastroenterol. 2014, 20, 5808-5817. [CrossRef]

21. Gallimidi, A.B.; Fischman, S.; Revach, B.; Bulvik, R.; Maliutina, A.; Rubinstein, A.M.; Nussbaum, G.; Elkin, M. Periodontal pathogens Porphyromonas gingivalis and Fusobacterium nucleatum promote tumor progression in an oral-specific chemical carcinogenesis model. Oncotarget 2015, 6, 22613-22623. [CrossRef]

22. Whitmore, S.E.; Lamont, R.J. Oral bacteria and cancer. PLoS Pathog. 2014, 10, e1003933. [CrossRef] [PubMed]

23. Lee, K.; Roberts, J.S.; Choi, C.H.; Atanasova, K.R.; Yilmaz, O. Porphyromonas gingivalis traffics into endoplasmic reticulum-rich-autophagosomes for successful survival in human gingival epithelial cells. Virulence 2018, 9, 845-859. [CrossRef] [PubMed]

24. Erkan, M.; Kurtoglu, M.; Kleeff, J. The role of hypoxia in pancreatic cancer: A potential therapeutic target? Expert Rev. Gastroenterol. Hepatol. 2016, 10, 301-316. [CrossRef] [PubMed]

25. Vaziri-Gohar, A.; Zarei, M.; Brody, J.R.; Winter, J.M. Metabolic dependencies in pancreatic cancer. Front. Oncol. 2018, 8, 617. [CrossRef]

26. Goto, Y.; Arigami, T.; Kitago, M.; Nguyen, S.L.; Narita, N.; Ferrone, S.; Morton, D.L.; Irie, R.F.; Hoon, D.S. Activation of Toll-like receptors 2, 3, and 4 on human melanoma cells induces inflammatory factors. Mol. Cancer Ther. 2008, 7, 3642-3653. [CrossRef]

27. Yilmaz, O.; Verbeke, P.; Lamont, R.J.; Ojcius, D.M. Intercellular spreading of Porphyromonas gingivalis infection in primary gingival epithelial cells. Infect. Immun. 2006, 74, 703-710. [CrossRef]

28. Kornmann, M.; Ishiwata, T.; Itakura, J.; Tangvoranuntakul, P.; Beger, H.G.; Korc, M. Increased cyclin D1 in human pancreatic cancer is associated with decreased postoperative survival. Oncology 1998, 55, 363-369. [CrossRef]

29. Hermano, E.; Meirovitz, A.; Meir, K.; Nussbaum, G.; Appelbaum, L.; Peretz, T.; Elkin, M. Macrophage polarization in pancreatic carcinoma: Role of heparanase enzyme. J. Natl. Cancer Inst. 2014, 106. [CrossRef]

30. Sanderson, R.D.; Elkin, M.; Rapraeger, A.C.; Ilan, N.; Vlodavsky, I. Heparanase regulation of cancer, autophagy and inflammation: New mechanisms and targets for therapy. FEBS J. 2017, 284, 42-55. [CrossRef]

31. Sunde, P.T.; Olsen, I.; Gobel, U.B.; Theegarten, D.; Winter, S.; Debelian, G.J.; Tronstad, L.; Moter, A. Fluorescence in situ hybridization (FISH) for direct visualization of bacteria in periapical lesions of asymptomatic root-filled teeth. Microbiology 2003, 149, 1095-1102. [CrossRef] [PubMed]

32. Yilmaz, O.; Jungas, T.; Verbeke, P.; Ojcius, D.M. Activation of the phosphatidylinositol 3-kinase/Akt pathway contributes to survival of primary epithelial cells infected with the periodontal pathogen Porphyromonas gingivalis. Infect. Immun. 2004, 72, 3743-3751. [CrossRef] [PubMed]

33. Kuboniwa, M.; Hasegawa, Y.; Mao, S.; Shizukuishi, S.; Amano, A.; Lamont, R.J.; Yilmaz, O.P. gingivalis accelerates gingival epithelial cell progression through the cell cycle. Microbes Infect. 2008, 10, 122-128. [CrossRef] [PubMed]

34. Mann, K.M.; Ying, H.; Juan, J.; Jenkins, N.A.; Copeland, N.G. KRAS-related proteins in pancreatic cancer. Pharmacol. Ther. 2016, 168, 29-42. [CrossRef]

35. Adamska, A.; Domenichini, A.; Falasca, M. Pancreatic Ductal adenocarcinoma: Current and evolving therapies. Int. J. Mol. Sci. 2017, 18, 1338. [CrossRef]

36. Burns, E.; Bachrach, G.; Shapira, L.; Nussbaum, G. Cutting edge: TLR2 is required for the innate response to Porphyromonas gingivalis: Activation leads to bacterial persistence and TLR2 deficiency attenuates induced alveolar bone resorption. J. Immunol. 2006, 177, 8296-8300. [CrossRef]

37. Tribble, G.D.; Lamont, R.J. Bacterial invasion of epithelial cells and spreading in periodontal tissue. Periodontol. 2000 2010, 52, 68-83. [CrossRef]

38. Madianos, P.N.; Papapanou, P.N.; Nannmark, U.; Dahlen, G.; Sandros, J. Porphyromonas gingivalis FDC381 multiplies and persists within human oral epithelial cells in vitro. Infect. Immun. 1996, 64, 660-664. [CrossRef]

39. Peyssonnaux, C.; Boutin, A.T.; Zinkernagel, A.S.; Datta, V.; Nizet, V.; Johnson, R.S. Critical role of HIF-1alpha in keratinocyte defense against bacterial infection. J. Investig. Dermatol. 2008, 128, 1964-1968. [CrossRef]

40. Nakhjiri, S.F.; Park, Y.; Yilmaz, O.; Chung, W.O.; Watanabe, K.; El-Sabaeny, A.; Park, K.; Lamont, R.J. Inhibition of epithelial cell apoptosis by Porphyromonas gingivalis. FEMS Microbiol. Lett. 2001, 200, $145-149$. [CrossRef] 
41. Soto, C.; Bugueno, I.; Hoare, A.; Gonzalez, S.; Venegas, D.; Salinas, D.; Melgar-Rodriguez, S.; Vernal, R.; Gamonal, J.; Quest, A.F.; et al. The Porphyromonas gingivalis $\mathrm{O}$ antigen is required for inhibition of apoptosis in gingival epithelial cells following bacterial infection. J. Periodontal. Res. 2016, 51, 518-528. [CrossRef] [PubMed]

42. Li, Q.; Zhou, J.; Lin, L.; Zhao, H.; Miao, L.; Pan, Y. Porphyromonas gingivalis degrades integrin beta1 and induces AIF-mediated apoptosis of epithelial cells. Infect. Dis. (Lond.) 2019, 51, 793-801. [CrossRef] [PubMed]

43. Chen, Y.; Zhou, R.; Yi, Z.; Li, Y.; Fu, Y.; Zhang, Y.; Li, P.; Li, X.; Pan, Y. Porphyromonas gingivalis induced inflammatory responses and promoted apoptosis in lung epithelial cells infected with H1N1 via the Bcl2/Bax/Caspase3 signaling pathway. Mol. Med. Rep. 2018, 18, 97-104. [CrossRef] [PubMed]

44. Zhu, H.; Lu, S.; Wei, M.; Cai, X.; Wang, G. Identification of novel genes involved in gingival epithelial cells responding to Aggregatibacter actinomycetemcomitans and Porphyromonas gingivalis infections. Arch. Oral Biol. 2018, 96, 113-121. [CrossRef]

45. Bold, R.J.; Virudachalam, S.; McConkey, D.J. BCL2 expression correlates with metastatic potential in pancreatic cancer cell lines. Cancer 2001, 92, 1122-1129. [CrossRef]

46. Murthy, D.; Attri, K.S.; Singh, P.K. Phosphoinositide 3-Kinase signaling pathway in pancreatic ductal adenocarcinoma progression, pathogenesis, and therapeutics. Front. Physiol. 2018, 9, 335. [CrossRef]

47. Rodrigues, P.H.; Reyes, L.; Chadda, A.S.; Belanger, M.; Wallet, S.M.; Akin, D.; Dunn, W., Jr.; Progulske-Fox, A. Porphyromonas gingivalis strain specific interactions with human coronary artery endothelial cells: A comparative study. PLoS ONE 2012, 7, e52606. [CrossRef]

48. Tanner, A.C.; Haffer, C.; Bratthall, G.T.; Visconti, R.A.; Socransky, S.S. A study of the bacteria associated with advancing periodontitis in man. J. Clin. Periodontol. 1979, 6, 278-307. [CrossRef]

49. Ilievski, V.; Bhat, U.G.; Suleiman-Ata, S.; Bauer, B.A.; Toth, P.T.; Olson, S.T.; Unterman, T.G.; Watanabe, K. Oral application of a periodontal pathogen impacts SerpinE1 expression and pancreatic islet architecture in prediabetes. J. Periodontal. Res. 2017, 52, 1032-1041. [CrossRef]

50. Kiss, B.; Miko, E.; Sebo, E.; Toth, J.; Ujlaki, G.; Szabo, J.; Uray, K.; Bai, P.; Arkosy, P. Oncobiosis and microbial metabolite signaling in pancreatic adenocarcinoma. Cancers 2020, 12, 1068. [CrossRef]

51. Bauer, C.; Bauernfeind, F.; Sterzik, A.; Orban, M.; Schnurr, M.; Lehr, H.A.; Endres, S.; Eigler, A.; Dauer, M. Dendritic cell-based vaccination combined with gemcitabine increases survival in a murine pancreatic carcinoma model. Gut 2007, 56, 1275-1282. [CrossRef] [PubMed] 